\title{
Enabling microscale processing: combined Raman and absorbance spectroscopy for microfluidic on-line monitoring
}

\author{
Gilbert L. Nelson, ${ }^{*}, 2$ Hope E. Lackey, ${ }^{1}$ Job M. Bello, ${ }^{3}$ Heather M. Felmy, ${ }^{1}$ Hannah B. Bryan, ${ }^{1}$ Fabrice
} Lamadie, ${ }^{4}$ Samuel A. Bryan, ${ }^{*}, 1$ and Amanda M. Lines ${ }^{*}, 1$

${ }^{1}$ Pacific Northwest National Laboratory, 902 Battelle Boulevard, Richland, WA 99352

${ }^{2}$ College of Idaho, Department of Chemistry, 2112 Cleveland Blvd, Caldwell, ID 83605

${ }^{3}$ Spectra Solutions Inc. 1502 Providence Highway, Norwood, MA, 02062-4643.

${ }^{4}$ CEA, DES, ISEC, DMRC, Univ. Montpellier, Marcoule, France

\section{TABLE OF CONTENTS}

\section{There is a total of 8 pages in SUPPORTING INFORMATION, containing 3 figures and 2 tables}

Figure S-1 (Top Left) Schematic of flow path and spectroscopic probe directions. (Top Right) T-junction capillary tube connector. (Bottom Left) Microfluidic flow setup with 2 syringe pumps a T-junction connector and the microfluidic chip (MFD) retained in the adjustable stage. (Bottom Right) Microfluidic chip (MFD) with micro-UV-vis probe positioned at left edge pointing through the transverse microfluidic channel.

Figure S-2. The positioning of the micro-probe relative to the microfluidic chip for displaying the image of the droplet formation within the micro-channel. The image is displayed on the wall of the laboratory takes advantage of the fine focus of the laser excitation within the channel to form a "pin-hole" camera image of the microchannel displaying the flow pattern. The image is displayed on the wall of the laboratory adjacent to the Raman micro-probe and microfluidic device.

Figure S-3. A). Diagram of the flow pattern used within the microfluidic chip forming laminar flow regime; B) "Pin-hole" camera image of the formation of two phases as they emerged into the single channel within the chip showing the formation of aqueous and organic laminal regime within the microfluidic channel. Note: the dashed lines in figure B were added for clarity......

Table S-1. Composition of solutions before extraction (pre-contact) with 30\% TBP/dodecane organic phase and after extraction (post-contact aqueous phase and post-contact organic phase).

Table S-2. Measured aqueous phase nitrate concentrations (by Raman, taken from Figure 5), and Nd concentrations for both aqueous and organic phases (by absorbance, taken from Figure 7). . .8 


\section{ABSTRACT}

The SI section contains details of sample preparation; experimental details of microfluidic cell, the derivation of the relationship between distribution ratio and total aqueous nitrate concentration; optical fingerprints and building chemometric models; details of optical fingerprints and building chemometric models to quantify target species; and separation challenges associated with microfluidic separation systems.

\section{Sample Preparation}

Sample prep is described in the main text, where details regarding sample compositions are included in Table S1

Table S-1. Composition of solutions before extraction (pre-contact) with 30\% TBP/dodecane organic phase and after extraction (post-contact aqueous phase and post-contact organic phase).

\begin{tabular}{|c|c|c|c|c|c|c|c|}
\hline \multirow[t]{2}{*}{ Sample } & \multicolumn{3}{|c|}{$\begin{array}{l}\text { Pre-Contact Static Aqueous } \\
\text { Solution Concentrations } \\
\text { (Training Set) } \\
\text { Known Values }\end{array}$} & \multirow[t]{2}{*}{$\begin{array}{l}\text { Total Flow Time } \\
\text { for each } \\
\text { Aqueous/Organic } \\
\text { Solution Pair } \\
\text { (minutes) } \\
\end{array}$} & \multicolumn{2}{|c|}{$\begin{array}{l}\text { Post-Contact Static } \\
\text { Aqueous Solution } \\
\text { Concentrations } \\
\text { (Validation Set) } \\
\text { Measured Values }\end{array}$} & \multirow{2}{*}{$\begin{array}{c}\text { Post-Contact Static } \\
\text { Organic Solution } \\
\text { Concentrations }\end{array}$} \\
\hline & $\mathrm{Nd}(\mathrm{mM})$ & $\mathrm{NaNO}_{3}(\mathrm{M})$ & $\mathrm{HNO}_{3}(\mathrm{M})$ & & $\begin{array}{c}\text { Nd (mM) } \\
\text { UV-vis }\end{array}$ & $\begin{array}{c}\mathrm{NaNO}_{3} \\
(\mathrm{M}) \\
\text { Raman }\end{array}$ & \\
\hline 1 & 0.0 & 0.000 & 0.100 & & 0.0 & 0.00 & 0.0 \\
\hline 2 & 5.0 & 0.000 & 0.100 & & 5.0 & 0.00 & 0.0 \\
\hline 3 & 10.0 & 0.000 & 0.100 & & 10.0 & 0.00 & 0.0 \\
\hline 4* & 25.0 & 0.000 & 0.100 & 45.4 & 25.0 & 0.00 & 0.0 \\
\hline 5* & 25.0 & 2.001 & 0.100 & 45.4 & 22.4 & 2.00 & 2.6 \\
\hline 6* & 25.0 & 2.502 & 0.100 & 45.4 & 20.8 & 2.60 & 4.2 \\
\hline 7* & 25.0 & 4.002 & 0.100 & 45.4 & 13.6 & 4.10 & 11.4 \\
\hline $8^{*}$ & 25.0 & 5.001 & 0.100 & 45.4 & 10.0 & 5.20 & 15.0 \\
\hline 9 & 2.0 & 0.500 & 0.100 & & 2.0 & 0.60 & 0.0 \\
\hline 10 & 5.0 & 1.000 & 0.100 & & 5.0 & 1.10 & 0.0 \\
\hline 11 & 10.0 & 2.500 & 0.100 & & 9.0 & 2.50 & 1.0 \\
\hline 12 & 14.0 & 4.002 & 0.100 & & 10.0 & 4.20 & 4.0 \\
\hline $\begin{array}{r}* \text { Solut } \\
\text { flow exp } \\
\text { so }\end{array}$ & $\begin{array}{l}\text { s used for } \\
\text { ment, "flow } \\
\text { ions" }\end{array}$ & & & $\begin{array}{l}\text { For each organic } \\
\text { aqueous pair two } \\
\text { syringes containing } \\
0.98 \mathrm{~mL} \text { of each } \\
\text { solution were set up } \\
\text { to yield } 7-0.14 \mathrm{~mL} \\
\text { aliquots and an } \\
\text { alternating } 0.042 \\
\mathrm{~mL} / \text { min continuous } \\
\text { flow was run. Each } \\
\text { aliquot flowed for } \\
3.24 \text { minutes } \\
\text { totaling } 22.7 \\
\text { minutes for each } \\
\text { phase or } 45.4 \\
\text { minutes total for } \\
\text { each pair. }\end{array}$ & $\begin{array}{c}\text { Model } \\
\text { Statistics: } \\
\text { PLS } \\
3 \text { Latent } \\
\text { Var } \\
\text { RMSEC = } \\
0.76 \\
\text { RMSECV = } \\
0.85\end{array}$ & $\begin{array}{c}\text { Model } \\
\text { Statistics: } \\
\text { PLS } \\
4 \text { Latent } \\
\text { Var } \\
\text { RMSEC = } \\
0.12 \\
\text { RMSECV } \\
=0.14\end{array}$ & \\
\hline
\end{tabular}




\section{Alternating Flow Set-up}

Two programable syringe pumps (New Era 1000) were used to inject the organic and aqueous phases to the MFD. A total of $0.98 \mathrm{~mL}$ of each phase within a sample pair (extracted aqueous phase $(0.98 \mathrm{~mL})$ and the corresponding contacted organic phase $(0.98 \mathrm{~mL})$ ) was delivered before switching to a new aqueous/organic pair. The pumps were set to deliver 7 alternating $0.14 \mathrm{~mL}$ aliquots of each phase within the organic/aqueous sample pair. The alternating phases were created by alternate injection of each phase through a common T-connector (Figure S1 top right). The syringe used for delivery of each phase was a $1 \mathrm{~mL}$ HSW NormJect having a barrel diameter of $4.69 \mathrm{~mm}$.

Both syringe pumps were set to deliver $0.14 \mathrm{~mL}$ quantities of each phase at a rate of $0.042 \mathrm{~mL} / \mathrm{min}$. For each alternating aqueous/organic pair the organic phase $(0.14 \mathrm{~mL})$ was introduced first. This was followed immediately by activation of the aqueous pump. Each pump was then alternately activated with the following volume accumulations: $0.14 \mathrm{~mL}, 0.28 \mathrm{~mL}, 0.42 \mathrm{~mL}, 0.56 \mathrm{~mL}, 0.70 \mathrm{~mL}, 0.84 \mathrm{~mL}$, and $0.98 \mathrm{~mL}$. After reaching $0.98 \mathrm{~mL}$ dispensed on each pump the syringe was quickly switched out with aqueous and organic syringes filled with components of the next sample. During the switch-out the spectrometer was left collecting spectra. It is estimated that the switch and resetting of pumps took about twenty seconds, so the last 4 or five spectra of each sample was taken on a static solution.

\section{System setup}

Images of the microfluidic device setup can be seen in Figure S1 


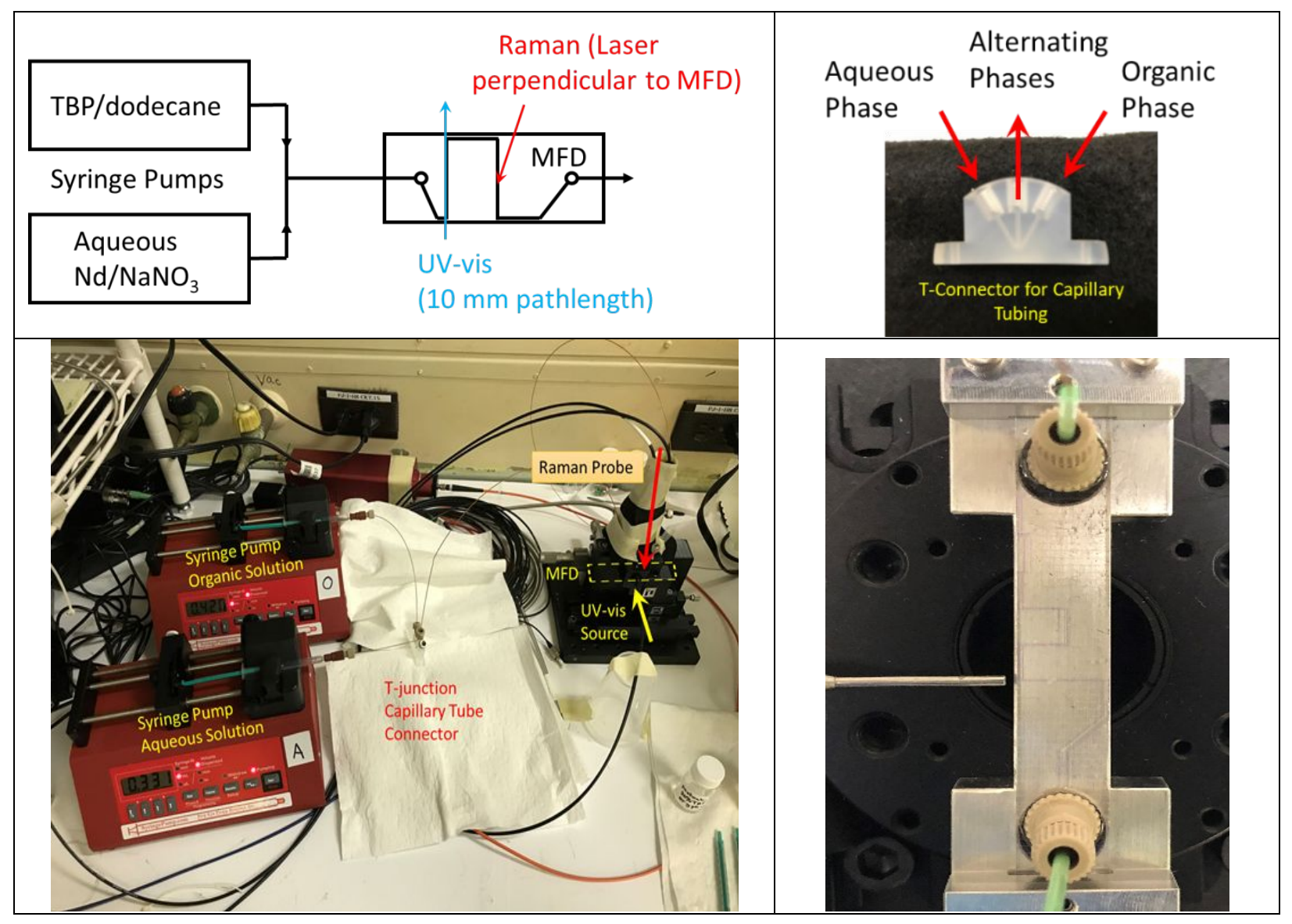

Figure S-1 (Top Left) Schematic of flow path and spectroscopic probe directions. (Top Right) T-junction capillary tube connector. (Bottom Left) Microfluidic flow setup with 2 syringe pumps a T-junction connector and the microfluidic chip (MFD) retained in the adjustable stage. (Bottom Right) Microfluidic chip (MFD) with micro-UV-vis probe positioned at left edge pointing through the transverse microfluidic channel.

\section{The derivation of the relationship between distribution ratio and total aqueous nitrate concentration}

The distribution of $\mathrm{Nd}$ between the aqueous and organic phases may be quantified using a distribution ratio, $D$, which is described by the following equation:

$$
D=\frac{\left[N d\left(\mathrm{NO}_{3}\right)_{3}\right]_{\text {org }}}{\left[\mathrm{Nd}^{3+}\right]_{a q}}
$$

Using an abbreviated form of the overall extraction equilibrium equation, an expression for an equilibrium constant, $\mathrm{K}_{\text {eq }}$, can be defined.

$$
\begin{gathered}
\mathrm{Nd}_{(a q)}^{3+}+3 \mathrm{NO}_{3(\mathrm{aq})}^{-} \rightleftharpoons \mathrm{Nd}\left(\mathrm{NO}_{3}\right)_{3(\mathrm{org})} \\
K_{e q}=\frac{\left[{\left.\mathrm{Nd}\left(\mathrm{NO}_{3}\right)_{3}\right]_{\text {org }}}_{\left[\mathrm{Nd}^{3+}\right]_{a q} \cdot\left[\mathrm{NO}_{3}^{-}\right]_{a q}^{3}}\right.}{}
\end{gathered}
$$


Rearranging this equation after applying a natural log function, $l n$, and then performing a second rearrangement gives rise to the following linear equation that relates the distribution ratio to the concentration of $\mathrm{NO}_{3}^{-}$in the aqueous phase. ${ }^{1}$

$$
\begin{aligned}
& \ln K_{e q}=\ln \frac{\left[\mathrm{Nd}^{\left.\left(\mathrm{NO}_{3}\right)_{3}\right]_{\text {org }}}\right.}{\left[\mathrm{Nd}_{(a q)}^{3}\right]}-3 \ln \left[\mathrm{NO}_{3}^{-}(\mathrm{aq})\right] \\
& \ln D=3 \ln \left[N O_{3(a q)}^{-}\right]+\ln K_{e q}
\end{aligned}
$$

This equation (Eqn S-5) predicts that the relationship between $\ln D$ and $\ln \left[\mathrm{NO}_{3}^{-}\right]_{a q}$ is linear with a slope of 3 when the values for each are plotted, ${ }^{1}$ which is consistent with the association of $3 \mathrm{NO}_{3}^{-}$complexed with $\mathrm{Nd}^{3+}$ from the aqueous phase and extracted as a $\mathrm{Nd}\left(\mathrm{NO}_{3}\right)_{3}$ organic phase complex.

\section{Identifying optical fingerprints and building chemometric models to quantify target species}

The UV-vis spectra shown in Figure 2A display the characteristic peaks associated with $\mathrm{Nd}$ at $520 \mathrm{~nm}, 580$ $\mathrm{nm}, 740 \mathrm{~nm}$, and $800 \mathrm{~nm} .^{2-4}$ An additional broad peak not related to Nd absorption just above $700 \mathrm{~nm}$ appears to some extent in some of the organic phase spectra. This was observed because spectra were recorded for both aqueous and organic phases in continuous succession, and a balance of UV-vis intensity was required to optimize the signal for both. The balance left the detector saturated for some organic spectra in the region just above $700 \mathrm{~nm}$. It was present for organic UV-vis spectra throughout the experiment but was compensated for easily with preprocessing in the chemometric modeling step.

Representative Raman spectra for both phases are shown in Figure 2B. Both phases give distinctive spectra. The aqueous phase is dominated by the $\mathrm{NO}_{3(a q)}^{-}$peak at about $1050 \mathrm{~cm}^{-1}$. ${ }^{5}$ The organic phase has several Raman peaks associated with $\mathrm{C}-\mathrm{H}$ bonding and shows very little indication of $\mathrm{NO}_{3}^{-}($org) presence at $1050 \mathrm{~cm}^{-1}$. For this study it is hypothesized that the presence of $\mathrm{NO}_{3}^{-}(\mathrm{org})$ is at very low concentrations in the organic phase, having a maximum value of about $75 \mathrm{mM}$ at the highest extraction rates and appears in the organic phase bound up as a Nd ligand. Taken together and given the presence of moderate peaks associated with the organic species also appearing at $1050 \mathrm{~cm}^{-1}$ it was concluded that $\mathrm{NO}_{3}^{-}$(org) was not distinguishable from the organic peaks under these extraction conditions. The measurement of $\mathrm{NO}_{3}^{-}(\mathrm{org})$ was not necessary for determining the parameters sought in this experiment.

\section{On-line monitoring of flowing separation process with alternating droplets of aqueous and organic solutions}

Especially pertinent here is the study of two-phase flows through a T-junction in the microfluidic channel since we alternated flow into the microfluidic chip of each phase using a T-junction. Down-stream flow patterns were influenced by the introduction of each phase in this fashion. A "squeeze" model features two immiscible phases flowing simultaneously into a common channel, and its characterization of the result is based on the volumetric flow ratio of the two phases. Though the demarcation is not exact, 
three flow regimes may be seen as the ratio of the continuous phase changes with respect to the flow rate of the dispersed phase. At high ratio - the continuous phase flowing at relatively high volumetric rate compared to the dispersed phase - droplets form into the continuous phase filled channel at the mouth of the T-junction with no necking between the entering bulk dispersed phase and the droplet. The high shear force applied from the flowing continuous phase immediately separates the droplet from the bulk. At lower flow ratios - similar volumetric flow rates between the continuous phase and the disperse phase - droplets also form at the inlet of the dispersed phase, but there is an apparent necking between the bulk and the droplet as the droplet is squeezed off and separates. For very low flow ratios as seen here - the continuous phase is flowing slowly compared to the disperse phase - the shear force is reduced to the point that a parallel flow is set up. The dispersed phase flows unbroken from its entry into the common channel to the exit point. The continuous phase which has largely occupied the common channel at the point the dispersed phase enters has wet the walls of the channel and maintains a film layer around the dispersed phase. The regions of the microfluidic channel occupied by the parallel flowing phases vary depending on the flow rates and presumably the surface tension between the phases and the viscous forces associated with each phase.

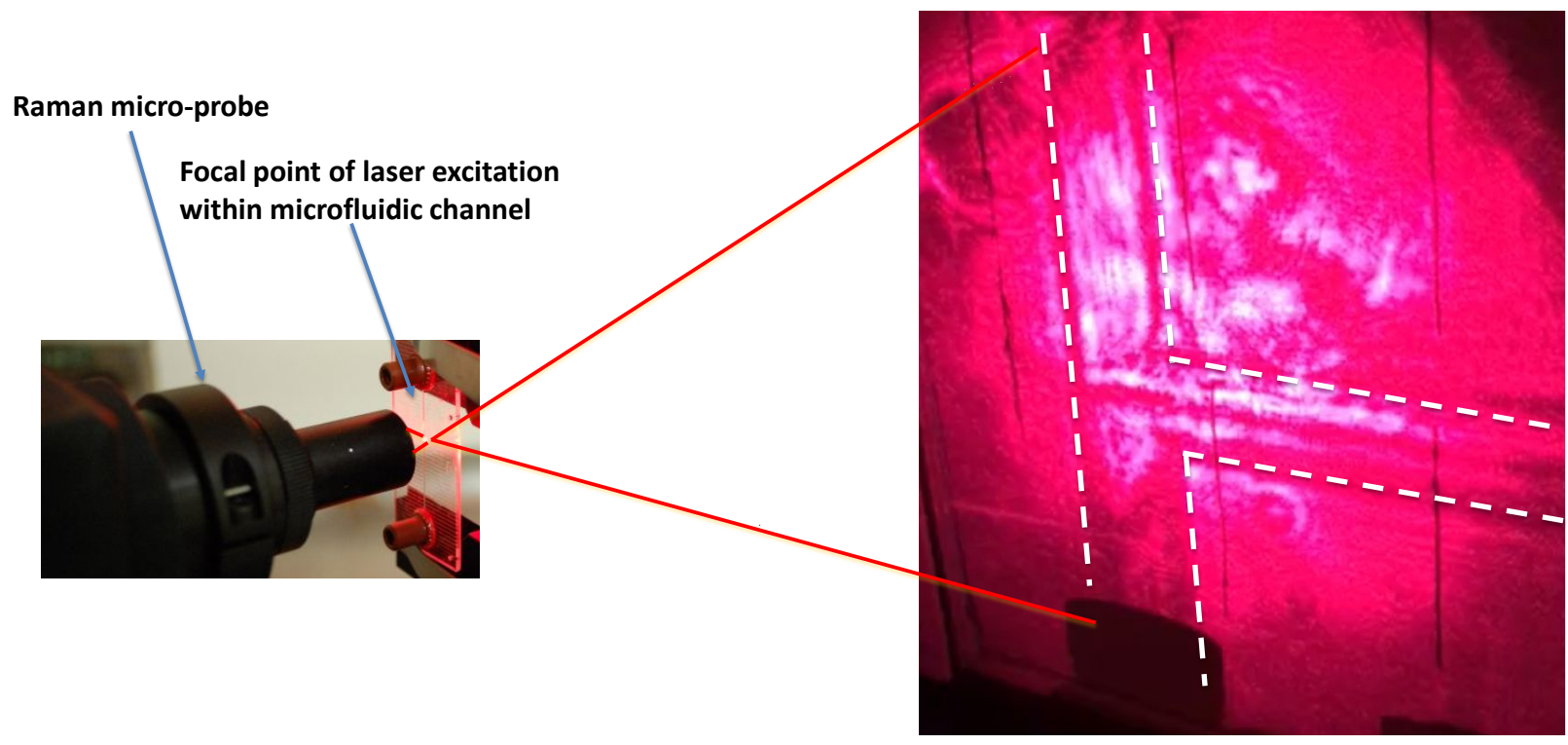

Figure S-2. The positioning of the micro-probe relative to the microfluidic chip for displaying the image of the droplet formation within the micro-channel. The image is displayed on the wall of the laboratory takes advantage of the fine focus of the laser excitation within the channel to form a "pin-hole" camera image of the microchannel displaying the flow pattern. The image is displayed adjacent to the Raman micro-probe and microfluidic device. 

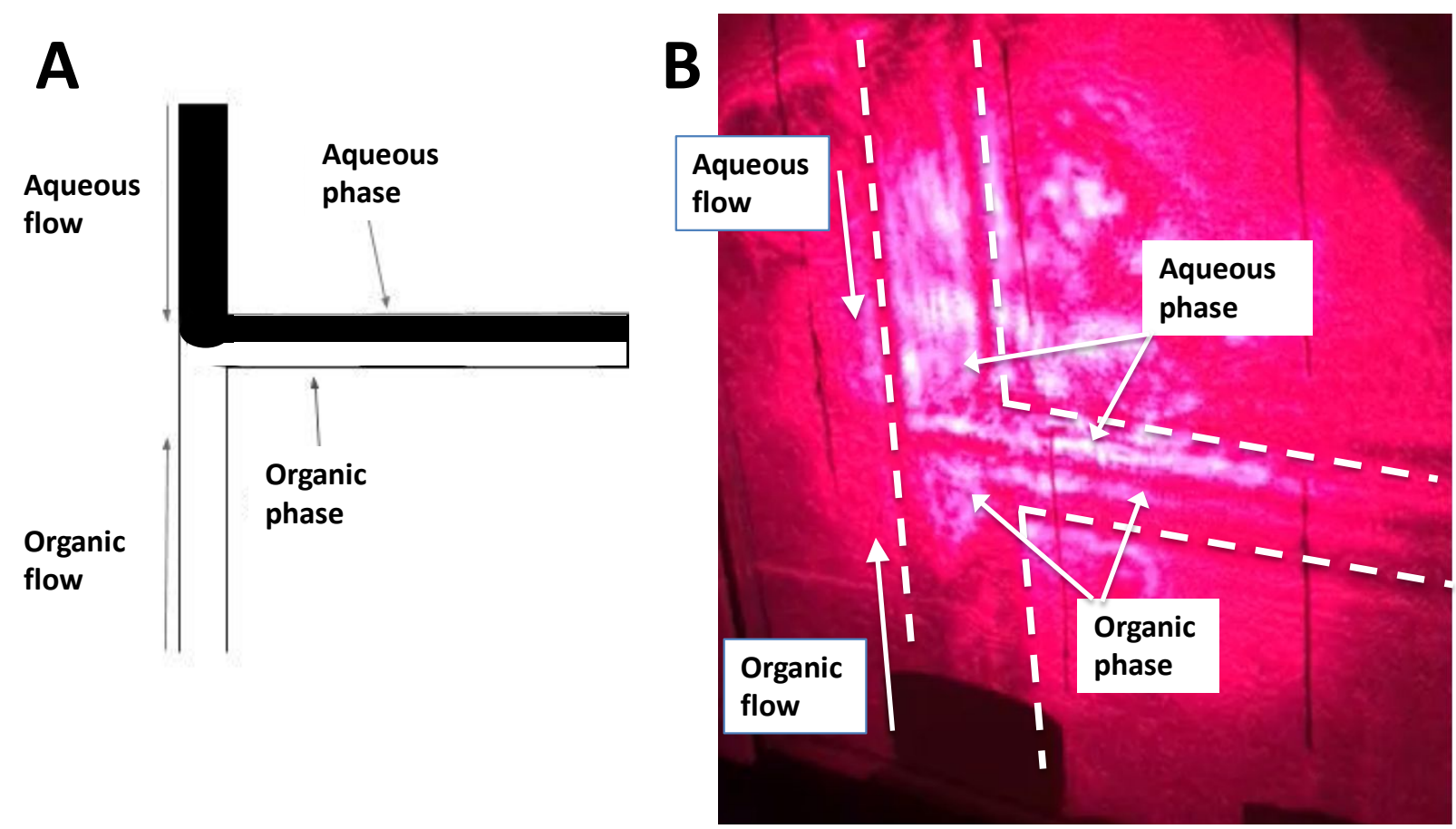

Figure S-3. A). Diagram of the flow pattern used within the microfluidic chip forming laminar flow regime; B) "Pin-hole" camera image of the formation of two phases as they emerged into the single channel within the chip showing the formation of aqueous and organic laminal regime within the microfluidic channel. Note: the dashed lines in figure B were added for clarity.

\section{Separation challenges associated with microfluidic separation systems}

For the experimental scheme set up here, the alternating phases provide very large differences between the volumetric flow rates of the different phases as each is alternately injected into the microfluidic channel at $0.042 \mathrm{~mL} / \mathrm{min}$ while the other is not injected at all. At each alternate injection of a phase the other phase which was previously injected to fill the common channel is the continuous phase. Over time the dispersed phase displaces the continuous phase. The rate that this occurs as revealed by spectroscopic analysis here is quite different for each phase. As the organic phase is injected as the dispersed phase (much lower density, much lower surface tension) it takes very little time to remove the wetting layer of the continuous aqueous phase and the organic phase seems to flow as almost a distinct plug flowing behind the aqueous phase. This is evidenced by an almost immediate full signal measurement of $\mathrm{Nd}$ present in the organic phase as soon as it passes through the UV-vis microfluidic sample channel. However, the as the aqueous phase is injected as the dispersed phase - higher density, higher surface tension - it achieves parallel flow but does not quickly remove the organic phase from the microfluidic channel. Examination of the Nd concentrations based on UV-vis spectra made as the aqueous phase reaches the common channel indicates that the aqueous phase only slowly displaces the organic phase. This is indicated by a steady increase in $\mathrm{Nd}$ signal as the organic phase is removed from the UV-vis sampling region. The maximum $\mathrm{Nd}$ measurement occurs here after most of the $0.14 \mathrm{~mL}$ aliquot of aqueous phase passes through the channel and toward the end of the injection period (see Figure 7) 
Other injection periods showed that the organic phase was never completely removed from the channel and the expected $\mathrm{Nd}$ concentration measurement was not attained.

The reduction of Raman signal accompanying an expected extraction of $75 \mathrm{mM} \mathrm{NO}_{3}^{-}(a q)$ into the organic phase only at the highest $\mathrm{NaNO}_{3}$ concentration of $5 \mathrm{M}$ would show little effect on the Raman intensity. The change would be much less for lower concentration samples having lower $\mathrm{NaNO}_{3}$ concentrations. Thus, the measured $\mathrm{NO}_{3}^{-}(a q)$ values for the extracted aqueous samples would be very similar to the precontact sample values. The modeling statistics (RMSEC: 0.085 and RMSECV: 0.098) give a rough estimate of the error for each measurement and indicate a change of $0.075 \mathrm{M}$ would be within that error. Table S-2 lists the average $\mathrm{NO}_{3}^{-}(a q)$ concentrations for the aqueous solutions measured by Raman, which are consistent with the concentrations of $\mathrm{NaNO}_{3}$ plus the baseline $0.1 \mathrm{M} \mathrm{HNO}_{3}$ mixed into the precontact aqueous solutions.

Table S-2. Measured aqueous phase nitrate concentrations (by Raman, taken from Figure 5), and Nd concentrations for both aqueous and organic phases (by absorbance, taken from Figure 7)

\begin{tabular}{|c|c|c|c|}
\hline $\begin{array}{l}\text { Flow } \\
\text { Solutions }\end{array}$ & $\begin{array}{l}\text { Aqueous Phase Flow [ } \\
\left.\mathrm{NO}_{3}^{-}\right](\mathrm{M}) \text { blue }\end{array}$ & $\begin{array}{l}\text { Aqueous Phase Flow } \\
{[\mathrm{Nd}](\mathrm{mM}) \text { blue }}\end{array}$ & $\begin{array}{l}\text { Organic Phase Flow } \\
{[\mathrm{Nd}](\mathrm{mM}) \text { red }}\end{array}$ \\
\hline 1 & 0.1 & 25.0 & 0 \\
\hline 2 & 2.1 & 22.4 & 4.1 \\
\hline 3 & 2.6 & 20.8 & 10.9 \\
\hline 4 & 4.1 & 13.6 & 15.0 \\
\hline 5 & 5.1 & 10.0 & \\
\hline
\end{tabular}

1. Rydberg, J.; Musicas, C.; Choppin, G. R., Principals and practices of solvent extraction. Marcel Dekker Inc.: New York, NY, 1992.

2. $\quad$ But, S.; Lis, S.; Van Deun, R.; Parac-Vogt, T. N.; Gorller-Walrand, C.; Binnemans, K., Spectroscopic properties of neodymium(III)-containing polyoxometalates in aqueous solution. Spectroc. Acta Pt. A-Molec. Biomolec. Spectr. 2005, 62 (1-3), 478-482.

3. Li, M.; Hao, Z. H.; Peng, X. N.; Li, J. B.; Yu, X. F.; Wang, Q. Q., Controllable energy transfer in fluorescence upconversion of NdF3 and NaNdF4 nanocrystals. Optics Express 2010, 18 (4), 3364-3369.

4. Narro-Garcia, R.; Desirena, H.; Lopez-Luke, T.; Guerrero-Contreras, J.; Jayasankar, C. K.; Quintero-Torres, R.; De la Rosa, E., Spectroscopic properties of Eu3+/Nd3+ co-doped phosphate glasses and opaque glass-ceramics. Opt Mater 2015, 46, 34-39.

5. Nakamoto, K., Infrared and Raman Spectra of Inorganic and Coordination Compounds: Theory and applications in inorganic chemistry. John Wiley: 1997. 